\title{
Serratia marcescens
}

National Cancer Institute

\section{Source}

National Cancer Institute. Serratia marcescens. NCI Thesaurus. Code C14272.

A species of motile, Gram-negative enterobacteria in the phylum Proteobacteria,

differentiated from other Gram-negative bacteria by its ability to perform casein hydrolysis. 